\title{
BRINGING THE MARKET INSIDE THE FIRM?
}

\author{
George Baker \\ Harvard Business School and NBER \\ Robert Gibbons \\ MIT's Sloan School and NBER \\ Kevin J. Murphy \\ University of Southern California
}

January 10, 2001 


\title{
Bringing The Market Inside The Firm?*
}

\author{
by George Baker, Robert Gibbons, and Kevin J. Murphy
}

Academics, consultants, and practitioners have long advocated bringing the market inside the firm. For example, in the 1950s and 1960s economists proposed that the transfer-pricing problem should be solved by charging market prices for internal transactions. Similarly, in the 1980s, financial economists suggested that the capital-allocation problem should be solved by charging the external cost of capital for internal investments. And wave after wave of organizational restructuring has advocated radical decentralization, empowerment, "intrapreneurship," and the like-in short, making employees feel like owners.

Proponents of making transactions within firms more market-like often seem to ignore the factors that brought these transactions inside firms in the first place. But Bengt Holmstrom and Paul Milgrom (1991, 1994), Holmstrom and Jean Tirole (1991), and Holmstrom (1999) [hereafter collectively HMT] remind us that in some cases integration is efficient precisely because it eliminates market incentives. In such cases, bringing the market inside the firm would clearly be undesirable.

In this paper we show that bringing the market inside the firm is often not feasible, even if it would be desirable. More precisely, if some aspects of the market transaction are non-contractible (as we define below) then it is impossible to replicate spot-market payoffs inside a firm. This result would be trivial if the firm's only instruments were court-enforceable contracts: it is impossible (by definition) for such contracts to replicate payoffs that were non-contractible in a spot market. Our

\footnotetext{
We thank Nancy Beaulieu, Bengt Holmstrom, and Michael Riordan for helpful comments. Baker: Harvard Business School, Soldiers Field, Boston MA 02163 (email: gbaker@hbs.edu); Gibbons: MIT's Sloan School, Cambridge, MA 02142 (email: rgibbons@ mit.edu).; Murphy: USC Marshall School of Business, MC 1427, Los Angeles, CA 90089-1427 (email: kjmurphy@usc.edu).
} 
contribution is to show that this result also applies to relational contracts (i.e., self-enforcing agreements in repeated games).

To establish this result we follow Sanford Grossman and Oliver Hart (1986), Hart and John Moore (1990), and Hart (1995) [hereafter collectively GHM] in using asset ownership to determine whether a particular transaction is inside a firm, and HMT in adding court-enforceable contracts to asset-ownership models. We also draw on our own work-George Baker, Robert Gibbons, and Kevin J. Murphy (2001) — to model relational contracts. ${ }^{1}$ The resulting model is the first we know that simultaneously analyzes asset ownership, court-enforceable contracts, and relational contracts.

We describe our economic environment in Section I, analyze spot markets and spot employment in Section II, and examine relational employment contracts in Section III. Section IV concludes.

\section{The EnVironment}

The economic environment consists of an upstream party, a downstream party, and an asset. In each period of a repeated game, the upstream party uses the asset to produce a good (which lasts for that period only). If the upstream party owns the asset then we call the transaction nonintegrated (the upstream party is an independent contractor, working with an asset she owns), whereas if the downstream party owns the asset then we call the transaction integrated (the upstream party is an employee, working with an asset owned by the firm).

We analyze two sources of incentives in spot markets: formal (i.e., solely reliant on courtenforceable contracts) and informal (i.e., involving non-contractual mechanisms such as bargaining or hold-up). To do so, we assume that the transaction includes both contractible and noncontractible components. The non-contractible component of the good is modeled as in Baker,

1 Early repeated-game models of relational contracts include Benjamin Klein and Keith Leffler (1981), Clive Bull (1987), and Bentley MacLeod and James Malcomson (1989). Baker, Gibbons, and Murphy (1994) study the interaction between court-enforceable and relational contracts; Maija Halonen (1994), Gerald Garvey (1995), and Baker, Gibbons, and Murphy (2001) study the interaction between asset ownership and relational contracts. 
Gibbons, and Murphy (2001) [hereafter BGM]: (1) it has value Q to the downstream party but also has value $\mathrm{P}$ in an alternative use; (2) the asset is specific, in the sense that $\mathrm{Q}>\mathrm{P}$; and (3) $\mathrm{Q}$ and $\mathrm{P}$ are not contractible but are observable to the upstream and downstream parties and so can be the basis of a relational contract in a repeated game. To add the contractible component of the good to the model, we assume that the good has characteristics $\mathrm{X}$ that are contractible and so can be the basis of a court-enforceable contract $\mathrm{w}(\mathrm{X})$ even in a one-shot transaction.

It would be natural to assume that the good's contractible characteristics have some value to the downstream party, and perhaps also some value in an alternative use. For simplicity in this short paper, however, we assume that these characteristics have no value in and of themselves, to the downstream party or anyone else. Thus, the parties' only interest in the contractible component of the good is that the actions taken to achieve $\mathrm{X}$ may also affect the likelihoods of $\mathrm{Q}$ and $\mathrm{P}$ (and/or the costs of other actions that affect these likelihoods), as follows. Each period, the upstream party chooses a vector of actions $\mathbf{a}=\left(\mathrm{a}_{1}, \mathrm{a}_{2}, \ldots, \mathrm{a}_{\mathrm{N}}\right)$ that stochastically affect $\mathrm{Q}, \mathrm{P}$, and $\mathrm{X}$. These actions cost the upstream party c(a). Given the actions, Q, P, and X are conditionally independent. The possible values of $Q, P$, and $X$ are finite: $Q \in\left\{Q_{1}, \ldots, Q_{K}\right\}, P \in\left\{P_{1}, \ldots, P_{J}\right\}$, and $X \in\left\{X_{1}, \ldots, X_{M}\right\}$.

Given this framework, we can formalize the idea that Q and P are not contractible: there is no function $g(\bullet)$ mapping $\left\{X_{1}, \ldots, X_{M}\right\}$ into $\left\{Q_{1}, \ldots, Q_{K}\right\}$ such that the conditional distribution of $g(X)$ given $\mathbf{a}$ is identical to the conditional distribution of Q given a, and likewise for P. Because we use the Nash bargaining solution below, it will also be important that for some fixed value of $\alpha$, $\alpha \mathrm{Q}+(1-\alpha) \mathrm{P}$ is not contractible, defined in the analogous way.

In addition to describing the contractibility of $\mathrm{X}, \mathrm{Q}, \mathrm{P}$, and $\alpha \mathrm{Q}+(1-\alpha) \mathrm{P}$, we must also specify the contractibility of trade. We assume that ownership of the asset conveys ownership of (both components of) the good produced using the asset. But we also assume that trade in the contractible component is contractible, whereas trade in the non-contractible component is not contractible. For example, if the downstream party owns the asset then he could simply take both components of the good, paying only the contractible fee $\mathrm{w}(\mathrm{X})$ but refusing to pay the upstream party anything further. 
Alternatively, if the upstream party owns the asset then she could collect the contractible fee w(X) but deliver only the contractible component, threatening to consign the non-contractible component of the good to its alternative use. Note that we use the same notation $w(X)$ to mean slightly different contracts in these two cases: if downstream owns the asset then $w(X)$ is simply an agency contract specifying payment $\mathrm{w}$ for results $\mathrm{X}$; if upstream owns the asset then $\mathrm{w}(\mathrm{X})$ is the payment specified if upstream transfers ownership of a contractible component with characteristics X.

As quick examples of our two-component framework, consider R\&D, software development, and consulting. In such settings, an outside expert may be hired to conduct a project for a client. If the expert meets the specifications written in the contract then the expert must be paid. But suppose that in meeting the contract specifications the expert also develops an unanticipated by-product that would be valuable to the client. ${ }^{2}$ If this by-product is not covered in the original contract then the outside expert is free not to sell it to the client, and may be free to sell it to other users. If the expert were an internal employee, on the other hand, then the client would own everything produced by the expert, whether covered in the original contract or not. ${ }^{3}$

Our assumption that trade in the non-contractible component is non-contractible is necessary to incorporate ex post bargaining in the spirit of GHM. In contrast, consider the familiar quantityquality distinction, where quality is non-contractible, but quantity as well as trade in the quantityquality bundle is contractible. The upstream party can surely shirk on quality, but cannot produce high quality and then threaten not to deliver it. Absent this threat, there is no ex post bargaining over non-contractible product quality.

2 Our model and examples envision contemporaneous co-production of the contractible and non-contractible components of the good. Other examples involve sequential co-production: producing the contractible component in the first phase of a project facilitates the production of the non-contractible component in a second phase of the project. Space constraints prevent us from exploring sequential co-production here, but we interpret our contemporaneous co-production model as a reduced form for many sequential cases.

3 There are of course contracts that reduce an outside expert's ability to sell unanticipated by-products to other users, but such contracts are typically incomplete. Likewise, there are limits on how securely a firm can own the ideas of its employees. In both cases, however, the client has more control over an internal employee than over an outside expert. This is the difference we model, again in a reduced-form way. 
We find our two-component model both theoretically compelling and empirically relevant. Regarding theory, something of this kind is necessary in order to blend court-enforceable contracts with asset ownership. That is, under non-integration the upstream party must be able to withhold something from the downstream party or the GHM-style ex post bargaining will not occur. And empirically, if one believes that such ex post bargaining is a real feature of non-integrated transactions, even in the presence of incomplete court-enforceable contracts, then one is forced towards something like our framework.

\section{Spot Outsourcing AND Spot Employment}

In this section we analyze the static version of our model. Consistent with common usage, we call the integrated case "employment," and the non-integrated case "outsourcing."

\section{A. Spot Employment}

Under spot employment the downstream party owns the asset but there is no relational contract. This case is a multi-task agency problem, similar to Holmstrom-Milgrom (1991). In the terminology introduced above, the only incentives in this case are formal. ${ }^{4}$

Because the downstream party owns the asset, he can simply take both components of the good while paying the upstream party only the contractible payment $\mathrm{w}(\mathrm{X})$. The upstream party therefore will choose actions $\mathbf{a}^{\mathrm{SE}}(\mathrm{w}(\bullet))$ to solve

$$
\underset{\mathrm{a}}{\operatorname{MAX}} \mathrm{E}_{\mathrm{X}}[\mathrm{w}(\mathrm{X}(\mathbf{a}))]-\mathrm{c}(\mathbf{a}) \equiv \mathrm{U}^{\mathrm{SE}}(\mathrm{w}(\bullet)),
$$

where $\mathrm{X}(\mathbf{a})$ denotes the random variable $\mathrm{X}$ given a (and likewise for $\mathrm{Q}(\mathbf{a})$ and $\mathrm{P}(\mathbf{a})$ below). The actions $\mathbf{a}^{\mathrm{SE}}(\mathrm{w}(\bullet))$ yield downstream surplus $\mathrm{D}^{\mathrm{SE}}(\mathrm{w}(\bullet)) \equiv \mathrm{E}_{\mathrm{Q}, \mathrm{X}}\left[\mathrm{Q}(\mathbf{a})-\mathrm{w}(\mathrm{X}(\mathbf{a})) \mid \mathbf{a}^{\mathrm{SE}}(\mathrm{w}(\bullet))\right]$. The parties choose the court-enforceable contract $\mathrm{w}(\bullet)$ to maximize $\mathrm{U}^{\mathrm{SE}}(\mathrm{w}(\bullet))+\mathrm{D}^{\mathrm{SE}}(\mathrm{w}(\bullet))$. Denote the

4 In our model there is no bargaining under integration because the downstream party owns the only asset. If we enriched the model to include the upstream party's human capital then there could be bargaining even under integration, but this bargaining would differ from that under non-integration. It is this difference in bargaining that we emphasize, not the absence of bargaining per se. 
efficient contract by $\mathrm{w}^{\mathrm{SE}}(\bullet)$, the induced actions by $\mathbf{a}^{\mathrm{SE}}$, and the resulting efficient total surplus by $\mathrm{S}^{\mathrm{SE}} \equiv \mathrm{D}^{\mathrm{SE}}+\mathrm{U}^{\mathrm{SE}}$.

\section{B. Spot Outsourcing}

Under spot outsourcing the upstream party owns the asset but there is no relational contract. This case involves ex post bargaining, similar to non-integration in a GHM model, but adds the possibility of court-enforceable contracts. Incentives in this case are thus both formal and informal.

Because the upstream party owns the asset, she can collect the contractible fee $w(X)$ but deliver only the contractible component of the good, threatening to consign the non-contractible component to its alternative use. Although upstream and downstream cannot contract on the realized values of $\mathrm{Q}$ and $\mathrm{P}$, they can negotiate ex post over the price of the non-contractible component. We use the Nash bargaining solution (with bargaining power $\alpha$ for the upstream party) to arrive at this price: downstream will pay upstream the alternative-use value, $\mathrm{P}$, plus $0<\alpha<1$ of the surplus from use by the downstream party, $\mathrm{Q}-\mathrm{P}$, so the price is $\alpha \mathrm{Q}+(1-\alpha) \mathrm{P}$.

The upstream party's payoff under spot outsourcing is thus $\mathrm{w}(\mathrm{X})$ plus the bargained price $\alpha \mathrm{Q}+(1-\alpha) \mathrm{P}$ less the cost of actions c(a), so she chooses actions $\mathbf{a}^{\mathrm{SO}}(\mathrm{w}(\bullet))$ to solve

$$
\underset{\mathrm{a}}{\operatorname{MAX}} \mathrm{E}_{\mathrm{X}, \mathrm{Q}, \mathrm{P}}[\mathrm{w}(\mathrm{X}(\mathbf{a}))+\alpha \mathrm{Q}(\mathbf{a})+(1-\alpha) \mathrm{P}(\mathbf{a})]-\mathrm{c}(\mathbf{a}) \equiv \mathrm{U}^{\mathrm{SO}}(\mathrm{w}(\bullet)) .
$$

After trade occurs, the downstream party's payoff is $\mathrm{Q}-\mathrm{w}-\alpha \mathrm{Q}-(1-\alpha) \mathrm{P}$. Define $\mathrm{D}^{\mathrm{SO}}(\mathrm{w}(\bullet)) \equiv$ $\mathrm{E}_{\mathrm{Q}, \mathrm{P}, \mathrm{X}}\left[(1-\alpha)\{\mathrm{Q}(\mathbf{a})-\mathrm{P}(\mathbf{a})\}-\mathrm{w}(\mathrm{X}(\mathbf{a})) \mid \mathbf{a}^{\mathrm{SO}}(\mathrm{w}(\bullet))\right]$. As above, the parties choose the court-enforceable contract $\mathrm{w}(\bullet)$ to maximize $\mathrm{U}^{\mathrm{SO}}(\mathrm{w}(\bullet))+\mathrm{D}^{\mathrm{SO}}(\mathrm{w}(\bullet))$. Denote the efficient contract by $\mathrm{w}^{\mathrm{SO}}(\bullet)$, the induced actions by $\mathbf{a}^{\mathrm{SO}}$, and the resulting efficient total surplus by $\mathrm{S}^{\mathrm{SO}} \equiv \mathrm{D}^{\mathrm{SO}}+\mathrm{U}^{\mathrm{SO}}$.

\section{Coasean Comparisons}

In the spirit of HMT, it is easy to construct examples in which spot employment is more efficient than spot outsourcing $\left(S^{S E}>S^{S O}\right)$ because integration eliminates market incentives. For instance, imagine that $\mathrm{X}=\mathrm{a}_{1}, \mathrm{Q}=\mathrm{a}_{1}+\mathrm{ka}_{2}$, and $\mathrm{P}=\mathrm{a}_{3}$, where $\mathrm{k}$ is sufficiently small. Then under 
non-integration the upstream party will pursue the socially wasteful activity $\mathrm{a}_{3}$, whereas under integration there will be contractual incentives for $\mathrm{a}_{1}$ only. For $\mathrm{k}$ sufficiently small, the omission of incentives for $\mathrm{a}_{2}$ under integration is preferable to the inclusion of incentives for $\mathrm{a}_{3}$ under nonintegration. In this case it would clearly be undesirable to replicate the market inside the firm.

In the spirit of GHM, it is easy to construct examples in which spot outsourcing is more efficient than spot employment $\left(S^{S E}<S^{S O}\right)$ because the market provides useful informal incentives via ex post bargaining. For instance, imagine that $\mathrm{X}=\mathrm{a}_{1}, \mathrm{Q}=\mathrm{a}_{1}+\mathrm{a}_{2}$, and $\mathrm{P}=\mathrm{a}_{2}$. Then under integration there will be contractual incentives for $a_{1}$ but no incentives for $a_{2}$, whereas nonintegration can achieve the first best: the upstream party will have incentives to pursue both $a_{2}$ (anticipating bargaining) and $\mathrm{a}_{1}$ (because of bargaining and a contract).

To launch the remainder of the paper, imagine that the initial economic environment was such that spot employment was more efficient than spot outsourcing, but that the parameters changed (permanently) so that spot outsourcing became more efficient. If there is a cost of dissolving the initial integrated firm then that firm would like to replicate the spot market without dissolving. Obviously, the firm cannot use only a formal contract $\mathrm{w}(\mathrm{X})$ to mimic the partially informal payoffs $\mathrm{w}^{\mathrm{SO}}(\mathrm{X})+\alpha \mathrm{Q}+(1-\alpha) \mathrm{P}$. But one might think that a firm could replicate the spot market's noncontractible payoffs via a relational contract. We turn next to this issue.

\section{Relational EMployment}

In relational employment, as in spot employment, the downstream party owns the asset and there can be a formal contract $\mathrm{w}(\mathrm{X})$. But in relational employment there can also be a relational contract based on the realizations Q, P, and X. Such relational employment contracts can provide informal upstream incentives, provided that the parties value their reputations sufficiently. The core of our analysis is therefore checking whether reputation concerns outweigh the temptation to renege on a given relational employment contract. 
An important part of this calculation is the payoff after reneging. We analyze trigger-strategy equilibria, in which the party who did not renege refuses to enter into any new relational contract with the party who reneged. Because there are only two parties, this trigger-strategy assumption implies that the parties live under spot governance forever after one reneges. To determine whether such spot governance takes the form of a spot outsourcing or spot employment, we allow the parties to negotiate over asset ownership after reneging. Thus, the downstream party will retain ownership when $\mathrm{S}^{\mathrm{SE}}>\mathrm{S}^{\mathrm{SO}}$, but will sell the asset to the upstream party (at some bargained price $\pi$ ) when $\mathrm{S}^{\mathrm{SO}}>$ $\mathrm{S}^{\mathrm{SE}}$.

Consider the relational compensation contract $(\mathrm{w}, \mathrm{b})$, where $\mathrm{w}(\mathrm{X})$ is contractible compensation (including any fixed salary) and $\mathrm{b}(\mathrm{Q}, \mathrm{P}, \mathrm{X})$ is non-contractible. Suppose that the upstream party is confident that the downstream party will indeed pay $\mathrm{b}(\mathrm{Q}, \mathrm{P}, \mathrm{X})$ as promised. If the upstream party accepts the relational contract $(w, b)$ then she will choose a vector of actions $\mathbf{a}^{\mathrm{RE}}$ to solve

$$
\underset{\mathrm{a}}{\operatorname{MAX}} \mathrm{E}_{\mathrm{Q}, \mathrm{P}, \mathrm{X}}[\mathrm{w}(\mathrm{X}(\mathbf{a}))+\mathrm{b}(\mathrm{Q}(\mathbf{a}), \mathrm{P}(\mathbf{a}), \mathrm{X}(\mathbf{a}))]-\mathrm{c}(\mathbf{a}) \equiv \mathrm{U}^{\mathrm{RE}}(\mathrm{w}(\bullet), \mathrm{b}(\bullet)) .
$$

The expected downstream payoff is then

$$
\mathrm{E}_{\mathrm{Q}, \mathrm{P}, \mathrm{X}}\left[\mathrm{Q}\left(\mathbf{a}^{\mathrm{RE}}\right)-\mathrm{w}\left(\mathrm{X}\left(\mathbf{a}^{\mathrm{RE}}\right)\right)-\mathrm{b}\left(\mathrm{Q}\left(\mathbf{a}^{\mathrm{RE}}\right), \mathrm{P}\left(\mathbf{a}^{\mathrm{RE}}\right), \mathrm{X}\left(\mathbf{a}^{\mathrm{RE}}\right)\right)\right] \equiv \mathrm{D}^{\mathrm{RE}}(\mathrm{w}(\bullet), \mathrm{b}(\bullet)),
$$

so the total surplus generated under $(w(\bullet), b(\bullet))$ is $S^{R E} \equiv U^{R E}+D^{R E}$.

The non-contractible payment rule $b(\bullet)$ is self-enforcing if both parties choose to make the specified payment for all possible realizations of $\mathrm{Q}, \mathrm{P}$, and $\mathrm{X}$. The downstream party reneges if he refuses to pay the promised bonus $\mathrm{b}(\mathrm{Q}, \mathrm{P}, \mathrm{X})$ to the upstream party, instead simply taking the good and paying only $\mathrm{w}(\mathrm{X})$. The upstream party reneges on the relational-employment contract by refusing to accept a promised payment $b(\mathrm{Q}, \mathrm{P}, \mathrm{X})$ when it was offered (or by refusing to make a promised payment if $\mathrm{b}(\mathrm{Q}, \mathrm{P}, \mathrm{X})<0)$. Each party will honor the relational contract as long as the present value of honoring the contract exceeds the present value of reneging.

When $\mathrm{S}^{\mathrm{SO}}>\mathrm{S}^{\mathrm{SE}}$ (i.e., when the firm would like to replicate the spot market without incurring the dissolution cost), the upstream party will buy the asset from the downstream party for price $\pi$ 
after either party reneges, after which the upstream and downstream parties will earn $\mathrm{U}^{\mathrm{SO}}$ and $\mathrm{D}^{\mathrm{SO}}$, respectively. For the downstream party, the present value of honoring the contract is $-\mathrm{b}(\mathrm{Q}, \mathrm{P}, \mathrm{X})+$ $1 / \mathrm{r} \mathrm{D}^{\mathrm{RE}}$, so he will honor rather than renege on the relational contract when

$$
-b(Q, P, X)+\frac{1}{r} D^{R E} \geq \frac{1}{r} D^{S O}+\pi
$$

Similarly, the upstream party will honor rather than renege on the relational contract when

$$
\mathrm{b}(\mathrm{Q}, \mathrm{P}, \mathrm{X})+\frac{1}{\mathrm{r}} \mathrm{U}^{\mathrm{RE}} \geq \frac{1}{\mathrm{r}} \mathrm{U}^{\mathrm{SO}}-\pi
$$

If (1) holds for all $b(Q, P, X)$ then it must hold for the largest $b(Q, P, X)$, while if (2) holds for all $\mathrm{b}(\mathrm{Q}, \mathrm{P}, \mathrm{X})$ then it must hold for the smallest $\mathrm{b}(\mathrm{Q}, \mathrm{P}, \mathrm{X})$. Combining these two extreme versions of (1) and (2) yields a necessary condition for the relational contract $b(\bullet)$ to be self-enforcing when $\mathrm{S}^{\mathrm{SO}}>\mathrm{S}^{\mathrm{SE}}$ :

$$
\operatorname{MAX} b(Q, P, X)-\operatorname{MIN} b(Q, P, X) \leq \frac{1}{r}\left(S^{R E}-S^{S O}\right) .
$$

A parallel analysis yields an analogous necessary condition for the relational contract $b(\bullet)$ to be self-enforcing when $\mathrm{S}^{\mathrm{SE}}>\mathrm{S}^{\mathrm{SO}}$ :

$$
\operatorname{MAX} b(Q, P, X)-\operatorname{MIN} b(Q, P, X) \leq \frac{1}{r}\left(S^{R E}-S^{S E}\right) .
$$

Combing (3) and (4) yields a single necessary condition for a self-enforcing relational contract,

$$
\operatorname{MAX} b(Q, P, X)-\operatorname{MIN} b(Q, P, X) \leq \frac{1}{r}\left(S^{R E}-\operatorname{MAX}\left(S^{S E}, S^{S O}\right)\right)
$$

which allows us to prove our main result.

Proposition: It is not possible to replicate the payoffs from an informal spot market inside a firm. Formally, if $\alpha \mathrm{Q}+(1-\alpha) \mathrm{P}$ is non-contractible then any $(\mathrm{w}(\bullet), \mathrm{b}(\bullet))$ satisfying $\mathrm{w}(\mathrm{X})+$ $\mathrm{b}(\mathrm{Q}, \mathrm{P}, \mathrm{X})=\mathrm{w}^{\mathrm{S} 0}(\mathrm{X})+\alpha \mathrm{Q}+(1-\alpha) \mathrm{P}$ cannot satisfy (5).

The proof of our proposition follows from inspection of (5). If the firm offers $(\mathrm{w}(\bullet), \mathrm{b}(\bullet))$ satisfying $w(X)+b(Q, P, X)=w^{S 0}(X)+\alpha Q+(1-\alpha) P$ then the upstream party's actions will be identical to those in spot outsourcing, thus generating surplus $S^{\mathrm{RE}}=S^{\mathrm{S} 0}$. But $\alpha Q+(1-\alpha) \mathrm{P}$ is noncontractible so $\mathrm{b}(\mathrm{Q}, \mathrm{P}, \mathrm{X})$ cannot be constant. Thus, the left-hand side of (5) is strictly positive but 
the right hand side is either zero (if $S^{S O}>S^{S E}$ ) or strictly negative (if $S^{S E}>S^{S O}$ ). In short, replicating the spot market generates too little surplus to overcome its own reneging temptations.

\section{Discussion}

Our result that informal spot-market outcomes cannot be replicated within firms is a cautionary tale for those who would "bring the market inside the firm" via transfer pricing, performance measurement (such as "Economic Value Added"), empowerment, and the like. Lest this result seem too gloomy, however, note that it may still be possible for relational employment to improve on both spot alternatives, even if it cannot mimic spot outsourcing. For example, imagine that $\mathrm{X}=\mathrm{a}_{1}, \mathrm{Q}=\mathrm{a}_{1}+\mathrm{ka}_{2}$, and $\mathrm{P}=\mathrm{a}_{2}$. Spot employment will then use the formal contract $\mathrm{w}(\mathrm{X})$ to provide incentives for $a_{1}$ but not for $a_{2}$. Spot outsourcing will be more efficient than spot employment, providing incentives for $\mathrm{a}_{1}$ through a formal contract and informal incentives for $\mathrm{a}_{1}$ and $\mathrm{a}_{2}$ through the bargained payoff $\alpha \mathrm{Q}+(1-\alpha) \mathrm{P}$. But if $\mathrm{k}>1$ then incentives for $\mathrm{a}_{2}$ will be too low even in spot outsourcing; as a result, for sufficiently small $r$, a relational employment contract can increase incentives for $\mathrm{a}_{2}$ and so dominate both spot employment and spot outsourcing.

This example illustrates what Oliver Williamson (1985) calls "selective intervention:" replicating the useful features of market governance but intervening when necessary to avoid the market's inefficiencies. Williamson correctly argues that such selective intervention is not always possible (else we would observe only one enormous firm). This example shows that selective intervention can sometimes work, because firms use relational contracts not merely to replicate the informal incentives in markets, but to generate better incentives and higher surplus than could be generated in either spot outsourcing or spot employment.

It is natural for economists to be enamored with markets and skeptical of bureaucracies, so efforts to make internal transactions more market-like are understandable. But the evidence is overwhelming that horizontal and vertical transactions inside large organizations are typically quite unlike spot-market transactions. In particular, internal transactions often rely heavily on relational 
contracts. This paper and BGM are motivated by and consistent with this evidence: relational contracts are very important inside firms, not because they replicate spot-market payoffs, but because they allow firms to improve on market outcomes. 


\section{REFERENCES}

Baker, George, Robert Gibbons and Kevin J. Murphy, "Subjective Performance Measures in Optimal Incentive Contracts," Quarterly Journal of Economics, 1994, 109, pp. 1125-56.

Baker, George, Robert Gibbons, and Kevin J. Murphy, "Relational Contracts and the Theory of the Firm," Quarterly Journal of Economics, forthcoming 2001.

Bull, Clive, "The Existence of Self-Enforcing Implicit Contracts," Quarterly Journal of Economics, 1987, 102, pp. 147-59.

Garvey, Gerald, "Why Reputation Favors Joint Ventures over Vertical and Horizontal Integration: A Simple Model," Journal of Economic Behavior and Organization, 1995, 28, pp. 387-97.

Grossman, Sanford and Oliver Hart, "The Costs and Benefits of Ownership: A Theory of Vertical and Lateral Ownership,” Journal of Political Economy, 1986, 95, pp. 691-719.

Halonen, Maija, "Reputation and Allocation of Ownership," Working Paper, Helsinki School of Economics, 1994.

Hart, Oliver, Firms, Contracts, and Financial Structure, Oxford: Clarendon Press (1995).

Hart, Oliver, and John Moore, "Property Rights and the Nature of the Firm," Journal of Political Economy 1990, 98, pp. 1119-58.

Holmstrom, Bengt, "The Firm as a Subeconomy," Journal of Law, Economics, and Organization, 1999, 15, pp. 74-102.

Holmstrom, Bengt, and Paul Milgrom, "Multitask Principal-Agent Analyses: Incentive Contracts, Asset Ownership, and Job Design," Journal of Law, Economics, and Organization, 1991, 7, pp. 24-52.

Holmstrom, Bengt, and Paul Milgrom, “The Firm as an Incentive System,” American Economic Review, 1994, 84, pp. 972-91.

Holmstrom, Bengt, and Jean Tirole, “Transfer Pricing and Organizational Form," Journal of Law, Economics, and Organization, 1991, 7, pp. 201-28. 
Klein, Benjamin, and Keith Leffler, "The Role of Market Forces in Assuring Contractual Performance," Journal of Political Economy, 1981, 89, pp. 615-641.

MacLeod, Bentley and James Malcolmson, "Implicit contracts, Incentive Compatibility, and Involuntary Unemployment," Econometrica, 1989, 57, pp. 447-80.

Williamson, Oliver, The Economic Institutions of Capitalism, New York: Free Press, 1985. 